\title{
Vasospasm after transsphenoidal adenoma removal: risk factors and new treatment perspectives for this rare event
}

\author{
Vasospasmo tras resección transesfenoidal de adenoma: factores de \\ riesgo y perspectivas de tratamiento para esta complicación inusual
}

\author{
Patricia López Gómez', David Mato Mañas', José María Navasa Mellado², Jaime Viera Artiles \\ Sergio Obeso Aguera ${ }^{3}$, Fernando Antonio Pazos Toral', Carlos Bucheli Peñafiel', \\ Jesús Esteban García ${ }^{1}$, Rubén Martín Láez ${ }^{1}$
}

${ }^{1}$ Department of Neurosurgery, Hospital Universitario Marques de Valdecilla. Santander, Spain.
2 Department of Neurorradiology, Hospital Universitario Marques de Valdecilla. Santander, Spain.
${ }^{3}$ Department of Otorhinolaryngology, Hospital Universitario Marques de Valdecilla, Santander, Spain.
${ }^{4}$ Department of Endocrinology, Hospital Universitario Marques de Valdecilla. Santander, Spain.

Resumen

El vasospasmo es una complicación infrecuente tras un cirugía trasnesfenoidal (TS) de un adenoma hipofisario, por lo que su manejo no está claro. Presentamos un caso de vasospasmo tras una cirugía TS y debatimos sobre su etiología y tratamiento. Una mujer de 52 años se presentó con hirsutismo, sin síntomas neurológicos. Una RMN evidenció un macroadenoma hipofisario. La paciente se sometió a una cirugía endoscópica transesfenoidal. EI TC postoperatorio mostró una importante hemorragia subaracnoidea (HSA). Al séptimo día postoperatorio la paciente presentó una afasia mixta brusca. Una arteriografía urgente evidenció vasospasmo en la arteria cerebral media izquierda, por lo que se administró nimodipono intraarterial. Tras esto, el vasospasmo desapareció y la paciente se recuperó completamente. La clave para un manejo óptimo de esta rara complicación es un alto índice de sospecha. La presencia de HSA parece contribuir definitivamente en su desarrollo. Por ello, se recomienda un manejo similar al del vasospasmo por HSA aneurimática.

Palabras clave: Vasospasmo, adenoma, transesfenoidal, hemorragia subaracnoidea, nimodipino.

\section{Abstract}

Cerebral vasospasm is an uncommon complication following transsphenoidal surgery (TSS) of a pituitary adenoma. Therefore, neither its physiopathology nor its management are clear. We present a case of vasospasm after TSS and we discuss about its etiology and treatment. A 52-year-old woman presented with hirsutism, without neurologic symptoms. A MRI showed a pituitary macroadenoma. The patient underwent an endoscopic transsphenoidal approach. Post-operative CT scan revealed an extensive subarachnoid haemorrhage (SAH). On postoperative 7th day, she developed an abrupt mixed aphasia. An urgent arteriography showed left middle cerebral artery vasospasm, so intra-arterial nimodipine was administered. After that, vasospasm disappeared and the patient recovered completely. The key to successful management of this rare complication is a high index of suspicion. The presence of postoperative SAH seems to definitely contribute to its apparition. Therefore, treatment in concordance with protocols for vasospasm due to aneurysmal SAH is recommended.

Key words: Vasospasm, adenoma, transsphenoidal, subarachnoid haemorrhage, nimodipine.

Corresponding author:

Patricia López Gómez

Servicio de Neurocirugía, Hospital Universitario Marqués de Valdecilla.

Avenida de Valdecilla s/n. 39007. Santander, Spain.

Telefono: +34684301045

patricia91lpz@gmail.com 


\section{Introduction}

Cerebral vasospasm is a well-known complication following aneurysmal subarachnoid haemorrhage $(\mathrm{SAH})^{1,2}$. However, there are other less common etiologies such as traumatic $\mathrm{SAH}^{3}$, meningitis ${ }^{4}$, intraventricular haemorrhage from arteriovenous malformations ${ }^{5}$, unruptured aneurysms ${ }^{6}$, and following a tumour resection surgery ${ }^{7}$. Its development in this last case is a very uncommon complication. Most of reported cases developed after a craniotomy, being its appearance after a transsphenoidal surgery (TSS) a rare event that has mainly been described in the literature through case reports $^{8,9}$. Until now, less than 40 cases have been reported. However, almost all these patients were operated in the microscopic era and reports of vasospasm after an endoscopic endonasal approach are extremely rare ${ }^{10}$. The etiology and pathophysiology of this complication is not well understood and several risk factors have been proposed ${ }^{11}$. Given its low frequency, neither its diagnosis nor its management are not clearly defined, potentially leading to significant morbidity and mortality ${ }^{12}$.

As a result of a recent case occurred in our centre, we carried out a bibliographical review of clinical cerebral vasospasm after TSS, revealing discrepancies about the possible risk factors of this complication.

\section{Illustrative case}

A 52-year-old woman with history of smoking habit, hypertension, dyslipidaemia and type 2 diabetes mellitus presented with recent onset hirsutism. Physical examination revealed an acromegalic face, hirsutism on face and arms, neck acrochordons and goiter. No neurological deficits were found. Endocrinological studies revealed elevated $\mathrm{GH}$ and IGF-1 levels and cerebral magnetic resonance imaging showed an extensive sellar lesion consistent with a pituitary macroadenoma of $3 \times 3,4 \times 2,8 \mathrm{~cm}$ (craneo-caudal, transverse, antero-posterior) (Figure 1). The tumour showed extension to the suprasellar region, the sphenoidal sinus and both cavernous sinuses (Knosp grade IV). Despite the fact that the tumour contacted the optic chiasm, there were no evident signs of compression to the optic pathway.

Taking into account the extent of the lesion, a total resection was not considered feasible. Therefore, a multidisciplinary treatment approach was planned. First, a reduction of the tumour volume through the resection of the sellar and suprasellar component, leaving the intracavernous component, and complementary radiotherapy afterwards for the tumour residue.

The patient underwent an endoscopic, endonasal expanded transsphenoidal, transtuberculum approach for removal of the tumour. A macroscopic total resection of the sellar and suprasellar component was achieved, leaving a rest of tumour in both cavernous sinuses as planned. As a unique intraoperative incidence, an important venous bleeding was observed during resection of the suprasellar component, which was controlled with pressure and haemostatic materials. A multilayer reconstruction with synthetic materials was done, achieving a hermetic closure. A lumbar drainage was placed in order to prevent postoperative CSF leak. Postoperative CT scan showed a significant amount of blood in the subarachnoid space filling the basal cisterns, involving the left suprasellar, sylvian, ambiens and prepontine cisterns (Figure 2). There was no evidence of ventricular dilatation.

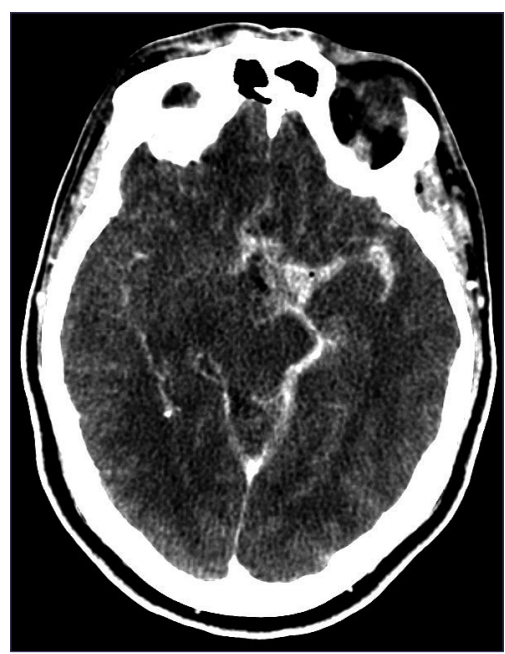

Figure 2. Postoperative $C T$ scan showed SAH filling basal cisterns.

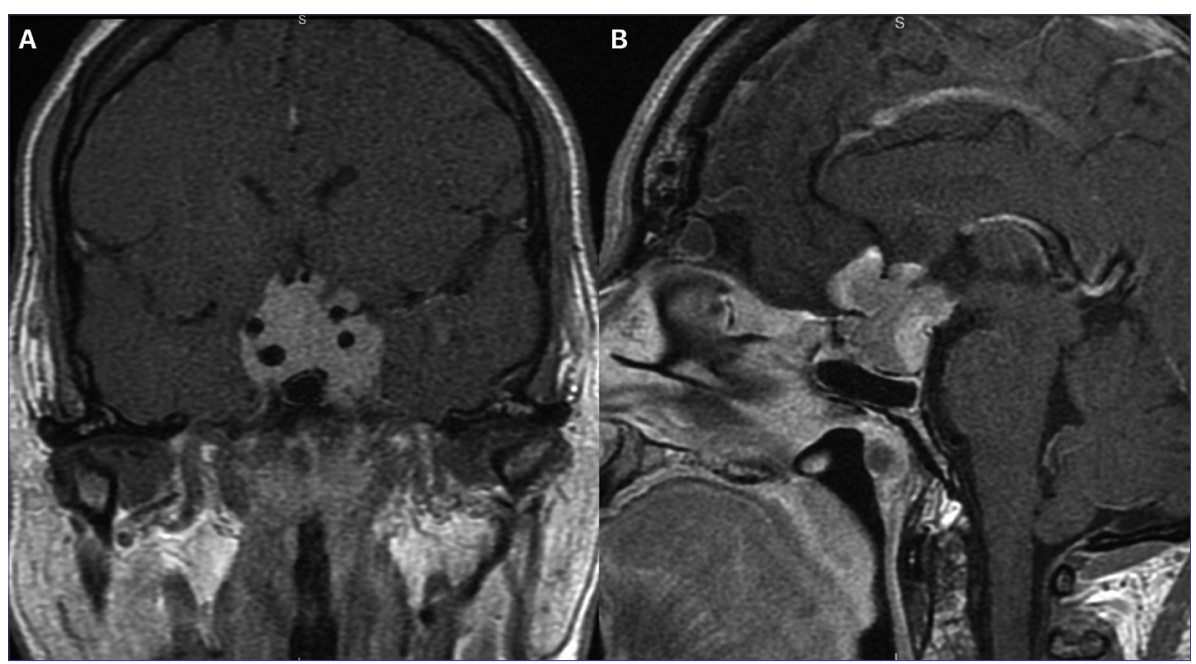

Figure 1. MRI T1weighted with contrast enhancement coronal (a) and sagittal (b) images showed a pituitary mass with suprasellar extension and cavernous sinus invasion, engulfing anterior communicating artery. 
During the immediate postoperative period the patient developed insipidus diabetes, which was successfully treated with desmopressin and intravenous fluid management. In addition, she presented hard-to-handle hypertension, with mean arterial pressures (MAP) around $130-150 \mathrm{mmHg}$. The initial approach was a monotherapy with an angiotensin-converting-enzyme inhibitor, but she then required to add urapidil rescues doses. Finally, MAP lowered to $80-90 \mathrm{mmHg}$ on the $6^{\text {th }}$ day post-surgery. The same day, since the CSF characteristics improved (lowered protein and red cells counting) the lumbar drain was removed. On the post-operative $7^{\text {th }}$ day, she presented an abrupt neurological deficit, with mixed aphasia, right facial palsy and right hemiparesis. An urgent CT scan and angio-CT scan revealed blood in the left Sylvian fissure and vasospasm of the left middle cerebral artery (MCA) from its origin to the M2-M3 segments (Figure 3).

An urgent arteriography was performed and it confirmed the vasospasm of the left MCA. Therefore, $6 \mathrm{mg}$ of intraarterial nimodipine were administered (Figure 4).

During the procedure, the neurological symptoms reappeared with the falls of blood pressure, so that an infusion of phenylephrine was initiated. Following the intraarterial therapy, the vasospasm disappeared and the patient gradually recovered to her neurological basal status. The patient was then treated with hypertension, haemodilution and hypervolemia therapy, intravenous nimodipine and vasoactive drugs. After 16 days without incidences, she was discharged without neurological deficits.

\section{Discussion}

Cerebral vasospasm after tumour resection is an uncommon complication ${ }^{9}$. It has been described after resection of pituitary tumours via transcranial and transsphenoidal ${ }^{8,9,11-19}$. So far, only 21 cases of vasospasm after TSS pituitary adenoma removal have been reported, and the most of them were operated in the microscopic era. We present a case of cerebral vasospasm after pituitary adenoma resection via

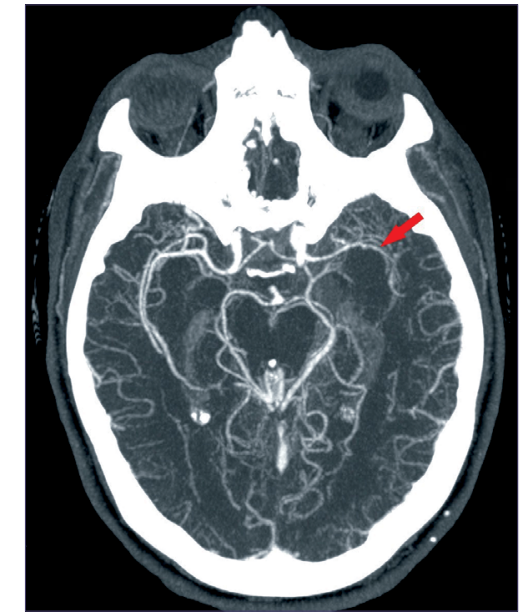

Figure 3. Angio CT-scan showing vasospasm of the left MCA (arrow).

endoscopic endonasal TSS.

Several risk factors have been proposed in previous reports $7,11,12,17$ :

- The presence of blood in the subarachnoid space ${ }^{11}$. In all of the reported cases there was a certain quantity of blood in the subarachnoid space. It is known that the subarachnoid blood leads to vasospasm after aneurysm rupture ${ }^{20}$. In fact, previous reports have pointed that the amount of blood correlates with the severity of the vasospasm ${ }^{21}$. This fact may indicate that the pathogenesis of postoperative vasospasm is not that dissimilar from vasospasm observed after aneurysmatic subarachnoid haemorrhage (aSAH). In fact, in our patient an important amount of blood was present in the basal cisterns near the Willis' circle arteries.

- Vessel manipulation ${ }^{12,14}$. Some previous reports pointed that mechanical manipulation of vasculature during the surgery could be a risk factor for development of clinically significant vasospasm ${ }^{22}$. However, in our case this manipulation did not occur, so we have doubts about this

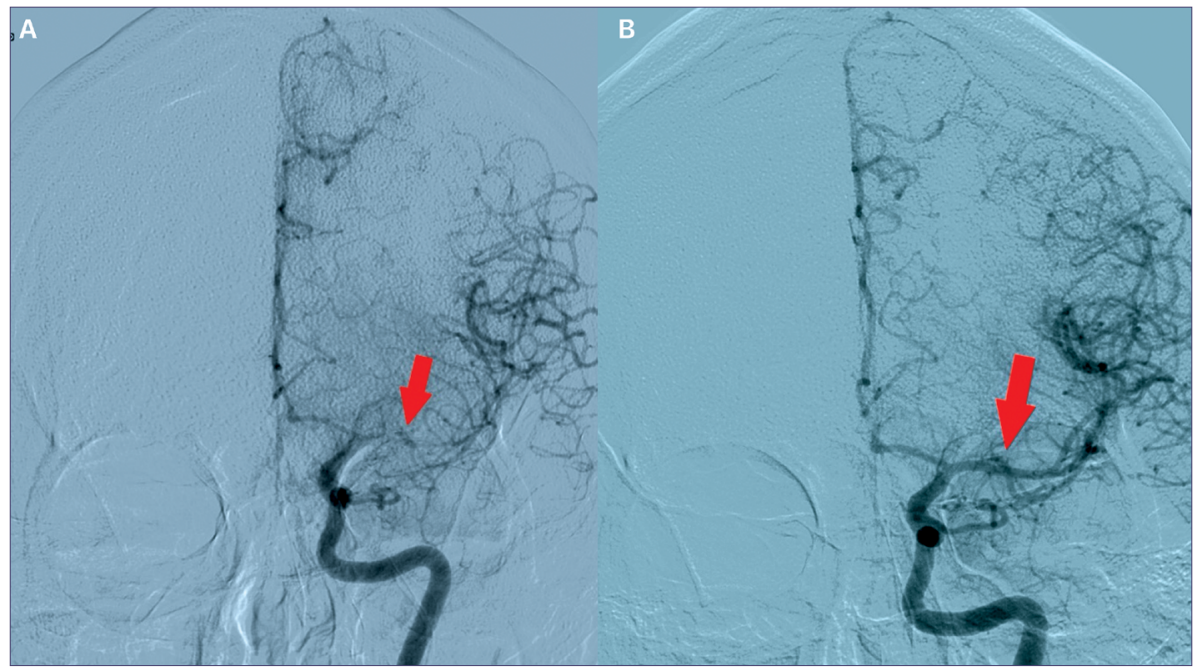

Figure 4. DSA confirmed vasospasm involving M2M3 segments of left MCA (a), that was successfully treated with $6 \mathrm{mg}$ of intraarterial nimodipine (b). 
proposed etiology. Furthermore, in our case vasospasm occurred in an entire hemisphere not only in the vessels near the tumour bed. In addition, the incidence of vasospasm after transcranial tumour surgery is very low, less than $1-2 \%$ according to the literature ${ }^{7}$, although vascular manipulation is greater in open surgeries. This supports that mechanical manipulation of vessels near the tumour cannot explain a generalized vasospasm.

- Tumour size. Some authors have pointed to tumour size and an important suprasellar component as an important risk factor because of the proximity of the Willis arteries ${ }^{7,12}$. Nevertheless the fact that large series of giant pituitary adenomas haven't reported vasospasm as a complication make us doubt about the tumour size as a risk factor ${ }^{23-25}$. In our experience, with more than 90 TSS some of them with larger dimensions, this is the first time we report this complication.

- Other reports point to substances released by the tumor $^{14,26}$. There is great variability among the cases described, finding $\mathrm{GH}, \mathrm{PRL}$ or ACTH producing adenomas, and non-functioning adenomas. This different nature of the adenomas involved without clearly predominance of any producing type makes weak this theory.

- Hypothalamic dysfunction is another cause described in the literature $\mathrm{e}^{12,27}$. Some authors aim that the hypothalamic direct damage during the surgery or its dysfunction caused by sympathetic activation can lead to secretion of spasmogenic factors ${ }^{10}$. Our patient developed diabetes insipidus, that can lead to the development of dehydration and volume contraction so it can facilitate the occurrence of vasospasm, but it is neither necessary nor sufficient condition $^{28}$.

- Hypotension. We highlight the fact that the clinical vasospasm appeared just after hypertension was correctly managed. Krayenbuehl et $\mathrm{al}^{15}$ in the first report of vasospasm after a tumour resection hypothesized about the post-operative hypotension as cause of this complication. In fact, hypertension is one of the most widespread treatments in cases of vasospasm after aSAH, supporting the idea that a low BP would help the development of vasospasm during the postoperative period.

- Lumbar drain has been proposed as a protective factor against vasospasm after aSAH ${ }^{29,30}$. A recent prospective and randomized trial showed that the drainage of CSF through a lumbar drain following aneurysmal SAH caused a statistically significant reduction in the incidence of clinical and radiological vasospasm and its sequelae and it also shortened the overall duration of hospital stay and improved the outcome ${ }^{31}$. The effectiveness of lumbar CSF drainage in aneurysmal $\mathrm{SAH}$ is believed to be related with the fact that it evacuates the large reservoir of bloody CSF from the spinal cistern, that it promotes CSF circulation from the ventricles through the subarachnoid spaces, and that it also removes the biochemical substances that mediate clinical vasospasm from subarachnoid space $^{29}$. Regarding the protective use of lumbar drainage against vasospasm after transsphenoidal surgeries, there is nothing published so far. In our case, vasospasm occurred 24 hours after the removal of the lumbar drainage, this fact raises the question of whether it could play a certain role in the development of this complication or be a mere temporary coincidence.

\section{Management}

The rarity of this complication leads to delay in diagno$\operatorname{sis}^{8,9,11}$. This fact can carry to a high morbidity and mortality ${ }^{11,32}$. An increased awareness is necessary to make an early diagnosis and treatment, that way we can achieve better outcomes at discharge. The follow up of that patients with risk factors to develop this event, such as SAH on CT and/or severe hypotension, should be similar to the one done after an aneurysmal $\mathrm{SAH}^{1,20}$. Periodic transcranial Doppler could be used as a key to early detection of the vasospasm and make a prompt treatment ${ }^{33}$.

\section{Treatment}

In the most part of the cases reported haemodilution, hypervolemic and hypertension therapy was used successfully, following the protocols for the treatment of an aneurysmal $\mathrm{SAH}^{8,9,11,34}$. That supports the fact that falls in the blood pressure can contribute to the development of symptomatic vasospasm. So, it seems reasonable to allow higher blood pressure levels in those patients with SAH on the post-operative CT scan.

Calcium-antagonist nimodipine is a well acknowledged therapy preventing vasospasm after aSAH and it was used in most part of cases of vasospasm after pituitary adenoma removal. However, even using it as a primary prevention some patients developed vasospasm ${ }^{35}$. Moreover, nimodipine, as a vasodilator, leads to hypotension, which should be carefully monitored in these patients ${ }^{10}$.

In some cases, intra-arterial spasmolytic like papaverine and verapamil were used as rescue therapy when intravenous

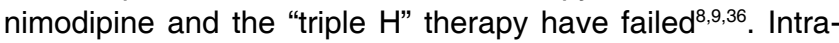
arterial papaverine (IAP) is a strong vasodilator that reduces angiographic vasospasm following an aSAH in most cases. However, owing to its short half-life, IAP has only a transient effect with the risk of recurrent or persistent vasospasm, necessitating repeated interventions ${ }^{37}$. In addition, the use of papaverine proved to have other limitations, including some adverse effects such an increase in intracranial pressure (ICP), worsening of vasospasm, brain stem depression, seizures, and transient focal neurological deficit ${ }^{38,39}$. Because of that, nowadays this agent is virtually obsolete in the management of cerebral vasospasm ${ }^{39}$.

Compared with papaverine calcium channel blockers, such verapamil or nimodipine, appear to have a more prolonged effect on arterial dilation and have not been associated with increases in $\mathrm{ICP}^{40}$. So, its use for the treatment for refractory vasospasm after aSAH has been extended. However, there are no prospective or comparative controlled studies ${ }^{41,42}$.

Our patient was initially treated with intra-arterial nimodipine. Recently this treatment has been reported to manage 3 cases of vasospasm after TSS adenoma removal with good results ${ }^{35}$.

Despite the absence of controlled studies and established protocols, it seems that intra-arterial nimodipine and other calcium channel blockers is safe and effective in the treatment 
of refractory cerebral vasospasm, so we must take them into account.

\section{Conclusion}

Vasospasm as a complication of a TSS is a rare event, but it can lead to an important morbidity and mortality. Because of that, a high level of suspicious is necessary to an early detection and management. Those patients with blood on the subarachnoid space should be followed closely, in a similar way to those with aneurysmal $\mathrm{SAH}$. This way we could achieve better outcomes.

Disclosure of interest: The authors report no conflict of interest

\section{References}

1. Findlay JM, Nisar J, Darsaut T. Cerebral Vasospasm: A Review. Can J Neurol Sci / J Can des Sci Neurol. 2016;43(01):15-32. doi:10.1017/cjn.2015.288

2. Al-Tamimi $Y Z$, Orsi NM, Quinn AC, Homer-Vanniasinkam S, Ross SA. A review of delayed ischemic neurologic deficit following aneurysmal subarachnoid hemorrhage: Historical overview, current treatment, and Pathophysiology. World Neurosurg. 2010;73(6):654-667. doi:10.1016/j.wneu.2010.02.005

3. Kramer DR, Winer JL, Pease BAM, Amar AP, Mack WJ. Cerebral vasospasm in traumatic brain injury. Neurol Res Int. 2013;2013:7 pages. doi:10.1155/2013/415813

4. Chaichana K, Riley LH, Tamargo RJ. Delayed cerebral vasospasm secondary to bacterial meningitis after lumbosacral spinal surgery: Case report. Neurosurgery. 2007;60(1). doi:10.1227/01. NEU.0000249193.68904.B4

5. Pendharkar A V, Guzman R, Dodd R, Cornfield D, Edwards MSB. Successful treatment of severe cerebral vasospasm following hemorrhage of an arteriovenous malformation. Case report. J Neurosurg Pediatr. 2009;4(3):266-269. doi:10.3171/2009.4.PEDS09126

6. Hohlrieder M, Spiegel M, Hinterhoelzl J, et al. Cerebral vasospasm and ischaemic infarction in clipped and coiled intracranial aneurysm patients. Eur J Neurol. 2002;9(4):389-399. doi:10.1046/j.1468-1331.2002.00425.x

7. Alotaibi NM, Lanzino G. Cerebral vasospasm following tumor resection. J Neurointerv Surg. 2013;5(5):413-418. doi:10.1136/ neurintsurg-2012-010477

8. Puri AS, Zada G, Zarzour H, Laws E, Frerichs K. Cerebral vasospasm after transsphenoidal resection of pituitary macroadenomas: Report of 3 cases and review of the literature. Neurosurgery. 2012;71(SUPPL.1):173-181. doi:10.1227/ NEU.0b013e31824aae21

9. Kim EH, Oh MC, Kim SH. Angiographically documented cerebral vasospasm following transsphenoidal surgery for pituitary tumors. Pituitary. 2013;16(2):260-269. doi:10.1007/s11102-0120415-7

10. Suero Molina E, Di Somma A, Stummer W, Briganti F, Cavallo $L M$. Clinical vasospasm after an extended endoscopic assisted approach for recurrent pituitary adenoma. Illustrative case and systematic review of the literature. World Neurosurg.
2019;128:29-36. doi:10.1016/j.wneu.2019.04.046

11. Eseonu Cl, Refaey K, Geocadin RG, Quinones-Hinojosa A. Postoperative Cerebral Vasospasm Following Transsphenoidal Pituitary Adenoma Surgery. World Neurosurg. 2016;92:7-14. doi:10.1016/j.wneu.2016.04.099

12. Bejjani GK, Sekhar LN, Yost AM, Bank WO, Wright DC. Vasospasm after cranial base tumor resection: pathogenesis, diagnosis, and therapy. Surg Neurol. 1999;52(6):574-577. doi:10.1136/ neurintsurg-2012-010477

13. Hyde-Rowan MD, Roessmann U, Brodkey JS. Vasospasm following transsphenoidal tumor removal associated with the arterial changes of oral contraception. Surg Neurol. 1983;20(2):120124. doi:10.1016/0090-3019(83)90461-5

14. Aoki N, Origitano TC, Al-Mefty O. Vasospasm after resection of skull base tumors. Acta Neurochir (Wien). 1995;132:53-58. doi:10.1007/BF01404848

15. Krayenbühl. A contribution to the problem of cerebral angiospastic insult. Schweiz Med Wochenschr. 1960;90:961-965.

16. Kasliwal MK, Srivastava R, Sinha S, Kale SS SB. Vasospasm after transsphenoidal pituitary surgery: A case report and review of the literature. Neurol India. 2008;56:81-83.

17. Gupta R, Sharma A, Vaishya R, Tandon M. Ischemic complications after pituitary surgery: A report of two cases. J Neurol Surgery, Part A Cent Eur Neurosurg. 2013;74:e119-e123. doi:http:// dx.doi.org/10.1055/s-0032-1328955

18. Camp PE, Paxton HD, Buchan GC GH. Vasospasm after Transsphenoidal Hypophysectomy. Neurosurgery. 1980;7(4):382-386.

19. Friedman JA, Meyer FB, Wetjen NM, Nichols DA. Balloon angioplasty to treat vasospasm after transsphenoidal surgery. Case illustration. J Neurosurg. 2001;95(2):353. doi:10.3171/ jns.2001.95.2.0353

20. Serrone JC, Maekawa H, Tjahjadi M, Hernesniemi J. Aneurysmal subarachnoid hemorrhage: pathobiology, current treatment and future directions. Expert Rev Neurother. 2015;15(4):367-380. do i: 10.1586/14737175.2015.1018892

21. Fisher CM, Kistler JP DJ. Relation of cerebral vasospasm to subarachnoid hemorrhage visualized by computerized tomographic scanning. Neurosurgery. 1980;6(1):1-9.

22. Page PS, Kim DD, Hall GC, Koutourousiou M. Cerebral Vasospasms Following Endoscopic Endonasal Surgery for Pituitary Adenoma Resection in the Absence of Post-Operative Subarachnoid Hemorrhage. 2016;4.

23. Gondim JA, Almeida JPC, Albuquerque LAF, Gomes EF, Schops M. Giant Pituitary Adenomas: Surgical Outcomes of 50 Cases Operated on by the Endonasal Endoscopic Approach. World Neurosurg. 2014;82(1-2):e281-e290. doi:10.1016/j. wneu.2013.08.028

24. Yano S, Hide T, Shinojima N. Efficacy and complications of endoscopic skull base surgery for giant pituitary adenomas. World Neurosurg. 2017. doi:10.1016/j.wneu.2016.12.068

25. Kuo CH, Yen YS, Wu JC, et al. Primary Endoscopic Transnasal Transsphenoidal Surgery for Giant Pituitary Adenoma. World Neurosurg. 2016;91:121-128. doi:10.1016/j.wneu.2016.03.092

26. Aw D, Aldwaik MA, Taylor TR, Gaynor C. Intracranial vasospasm with delayed ischaemic deficit following epidermoid cyst resection. Br J Radiol. 2010;83(991):135-137. doi:10.1259/ bjr/64333247

27. Wilson JL, Feild JR. The production of intracranial vascular spasm by hypothalamic extract. J Neurosurg. 1974;40(4):473479. doi:10.3171/jns.1974.40.4.0473 
28. Smith D, Finucane F, Phillips J, et al. Abnormal regulation of thirst and vasopressin secretion following surgery for craniopharyngioma. Clin Endocrinol (Oxf). 2004;61(2):273-279. doi:10.1111/j.1365-2265.2004.02086.x

29. Park S, Yang N, Seo E. The Effectiveness of Lumbar Cerebrospinal Fluid Drainage to Reduce the Cerebral Vasospasm after Surgical Clipping for Aneurysmal Subarachnoid Hemorrhage. J Korean Neurosurg Soc. 2015;57(3):167-173. doi:10.3340/ jkns.2015.57.3.167

30. Fang Y, Shao Y, Lu J, et al. The effectiveness of lumbar cerebrospinal fluid drainage in aneurysmal subarachnoid hemorrhage with different bleeding amounts. Neurosurg Rev. 2019. doi:10.1007/s10143-019-01116-1

31. Borkar S, Singh M, Kale S, et al. Spinal cerebrospinal fluid drainage for prevention of vasospasm in aneurysmal subarachnoid hemorrhage: A prospective, randomized controlled study. Asian J Neurosurg. 2018;13(2):238. doi:10.4103/1793-5482.228512

32. Bejjani GK, Sekhar LN, Yost AM, Bank WO, Wright DC. Vasospasm after cranial base tumor resection: Pathogenesis, diagnosis, and therapy. Surg Neurol. 1999;52(6):577-584. doi:10.1016/ S0090-3019(99)00108-1

33. Aaslid $\mathrm{R}$, Huber $\mathrm{P}$, Nornes $\mathrm{H}$. Evaluation of cerebrovascular spasm with transcranial Doppler ultrasound. J Neurosurg. 1984;60(1):37-41. doi:10.3171/jns.1984.60.1.0037

34. Raabe A, Beck J, Keller M, Vatter H, Zimmermann M, Seifert V. Relative importance of hypertension compared with hypervolemia for increasing cerebral oxygenation in patients with cerebral vasospasm after subarachnoid hemorrhage. J Neurosurg. 2005;103(6):974-981. doi:10.3171/jns.2005.103.6.0974

35. Osterhage K, Czorlich P, Burkhardt TR, Rotermund R, Grzyska
U, Flitsch J. Symptomatic Vasospasms as a Life-Threatening Complication After Transsphenoidal Surgery. World Neurosurg. 2018;110:180-188. doi:10.1016/j.wneu.2017.10.027

36. Nishioka $\mathrm{H}$, Ito $\mathrm{H}$, Haraoka J. Cerebral vasospasm following transsphenoidal removal of a pituitary adenoma. $\mathrm{Br} \mathrm{J}$ Neurosurg. 2001;15(1):44-47. doi:10.1080/0268869002002439

37. Hosmann A, Rauscher S, Wang W te, et al. Intra-Arterial Papaverine-Hydrochloride and Transluminal Balloon Angioplasty for Neurointerventional Management of Delayed-Onset PostAneurysmal Subarachnoid Hemorrhage Vasospasm. World Neurosurg. 2018;119:e301-e312. doi:10.1016/j.wneu.2018.07.138

38. Weant KA, Ramsey CN, Cook AM. Role of intraarterial therapy for cerebral vasospasm secondary to aneurysmal subarachnoid hemorrhage. Pharmacotherapy. 2010;30(4):405-417. doi:10.1592/phco.30.4.405

39. Pierot L, Aggour M, Moret J. Vasospasm after aneurysmal subarachnoid hemorrhage: Recent advances in endovascular management. Curr Opin Crit Care. 2010;16(2):110-116. doi:10.1097/ MCC.0b013e3283372ef2

40. Keuskamp J, Murali R, Chao KH. High-dose intraarterial verapamil in the treatment of cerebral vasospasm after aneurysmal subarachnoid hemorrhage. J Neurosurg. 2008;108(3):458-463. doi:10.3171/JNS/2008/108/3/0458

41. Feng L, Fitzsimmons BF, Young WL, et al. Intraarterially administered verapamil as adjunct therapy for cerebral vasospasm: Safety and 2-year experience. Am J Neuroradiol. 2002;23(8):1284-1290.

42. Kim JH, Park IS, Park KB, Kang DH, Hwang SH. Intraarterial nimodipine infusion to treat symptomatic cerebral vasospasm after aneurysmal subarachnoid hemorrhage. J Korean Neurosurg Soc. 2009;46(3):239-244. doi:10.3340/jkns.2009.46.3.239 